\title{
Tests Research on Grouting Materials of Waste-Concrete-Powder Cement for Goaf Ground Improvement
}

\author{
Zhilin Dun $\mathbb{D}^{1},{ }^{1,2}$ Mengqi Wang $\mathbb{D}^{1,2}$ Lianwei Ren $\left.{ }^{1}\right)^{1,2}$ and Zhiyuan Dun ${ }^{3}{ }^{3}$ \\ ${ }^{1}$ School of Civil Engineering, Henan Polytechnic University, Jiaozuo, Henan 454000, China \\ ${ }^{2}$ Henan Engineering Research Center of Ecological Restoration and Construction Technology in Goaf Site, Jiaozuo, \\ Henan 454000, China \\ ${ }^{3}$ School of Civil and Architectural Engineering, Jiaozuo University, Jiaozuo 454100, China \\ Correspondence should be addressed to Lianwei Ren; renhpu@163.com and Zhiyuan Dun; dzy207@163.com
}

Received 3 August 2021; Accepted 23 November 2021; Published 17 December 2021

Academic Editor: Robert Černý

Copyright (C) 2021 Zhilin Dun et al. This is an open access article distributed under the Creative Commons Attribution License, which permits unrestricted use, distribution, and reproduction in any medium, provided the original work is properly cited.

\begin{abstract}
Waste concrete powder (WCP) is proposed to replace part of the cement to seek environmentally friendly grouting materials for ground improvement in mine goaf. The optimal mixing proportion was selected based on the performance indexes of the waterseparation ratio, stone rate, viscosity, setting time, and compressive strength. X-ray diffraction (XRD) and scanning electron microscopy (SEM) tests were also conducted to analyze mineralogical phases and investigate the microscopic mechanism. Test results show that the slurry prepared by the substitution rate of $70 \%$ and adding $0.05 \%$ water-reducing agent meets well the requirements of ground grouting in mine goaf. The WCP produced by grinding mainly exerts microaggregate effect in the slurry due to low activity. A lot of pores on the surface of WCP were shown by SEM which can absorb the water in the slurry and increase the stone rate. The WCP application for ground grouting in mine goaf can not only recycle WC but also provide new grouting materials for goaf ground.
\end{abstract}

\section{Introduction}

China's mineral resources are rich and widely distributed. Large areas of goafs have been formed with the continuous exploitation of mineral resources. Serious geological disasters are often caused by the instability of goaf, which not only threatens the safety of human life and property but also breaks the original ecological balance of nature $[1,2]$. The ground in mine goaf is a geological unit consisting of the rock-soil body and the underlying mine goaf within the scope of additional stress of building foundation [3]. With the rapid economic development and the in-depth advancement of urbanization, urban land resources are becoming increasingly tight, and engineering construction on the goaf site has become an inevitable trend [4]. Research and treatment of the ground in mine goaf are an essential prerequisite for such activities.

Grouting technology is widely used in the field of geotechnical engineering and disaster prevention.
Geological disasters can be prevented by injecting slurry to fill and strengthen the rock-soil body [5]. There are two main types of grouting materials: chemical and cement-based. Ordinary Portland cement slurry is the most widely used grouting material due to the fact that chemical grouting usually contains toxicity, large environmental pollution, and poor controllability [6-8]. A large number of researchers have started to develop solid waste into grouting materials with the concept of green sustainability gaining popularity. Zhou et al. [9] used bentonite to replace $50 \%$ of cement to prepare cement-based slurry and used water glass as a coagulant to study the apparent viscosity, bleeding rate, setting time, and compressive strength of the slurry through laboratory tests. Test results show that the slurry has the excellent characteristics of high viscosity, low bleeding, short and controllable setting time, and high early strength. PerezGarcia et al. [10] used slag instead of cement to prepare slurry and studied its consistency, workability, leaching instability, and mechanical properties. Test results show that 
slag can replace up to $70 \%$ of cement, which not only saves cement but also provides a way to recycle slag from the steel industry. Zhu et al. [11] developed a new grouting material suitable for coal floor grouting reinforcement using waste tire rubber particles and fly ash as the main raw materials, providing a new way for the selection of grouting reinforcement materials for mine floor.

Ground grouting in mine goaf is different from general rock-soil body grouting, which mainly aims at filling the cavities, voids, and cracks in goaf and the overlying rock-soil body. The reinforcement mechanism is mainly based on filling and compaction, which has low requirements on material strength and certain requirements on fluidity, setting time, and stone rate of slurry [12]. Besides, large amounts of slurry and high cost of slurry materials are caused by the large-area filling of the ground in mine goaf. Therefore, grouting materials for ground in mine goaf is necessary to conduct special research to improve filling efficiency and save filling costs.

The annual construction waste generated by demolition may be billions of tons in China, but the average utilization rate is less than $5 \%$, which is far lower than the EU and other developed countries [13-15]. The proportion of waste concrete (WC) in construction waste is extremely high. WC is often crushed and screened into coarse and fine aggregates of different particle sizes, which are used to replace some natural aggregates to prepare recycled concrete [16-18]. Many researchers began to work on the recycling of waste concrete powder (WCP) due to the fact that the fine powder produced by crushed aggregates is often discarded and wasted [19]. Xiao et al. [20] recovered the powder generated from building demolition and used it to replace part of Portland cement to make recycled powder concrete. It was found that when the replacement rate did not exceed $30 \%$, the incorporation of recycled powder had little effect on the mechanical properties of concrete. Kwon et al. [21] used cementitious powder in waste concrete to produce recycled cement. The study found that cementitious powder in WC is difficult to separate from fine aggregate powder. To produce high-quality recycled cement, efficient separation technology needs to be developed so that the amount of fine aggregate powder mixed is less than $30 \%$. He et al. [22] used wet grinding technology to grind waste autoclaved aerated concrete from building demolition into ultrafine powder with a median particle size of $2.3 \mu \mathrm{m}$. The slurry was prepared by replacing a certain proportion of cement with the powder, and the mechanical properties of the slurry were measured. It was found that the compressive strength of cement slurry mixed with wet grinding powder was not lower than that of pure cement slurry when the replacement rate did not exceed $30 \%$.

The replacement rate is generally not more than $30 \%$ due to the fact that the activity of WCP after grinding is not high. According to the characteristics of ground grouting in mine goaf, a high substitution rate slurry suitable for ground treatment in mine goaf is proposed by mixing the WCP with cement, which not only can reduce the cost of slurry materials but also provides a new way to recycle WC.

\section{Materials and Methods}

2.1. Materials. The cement used in the test was 42.5 -grade ordinary Portland cement, and the water-reducing agent used was naphthalene system water-reducing agent. The main material used in the test was taken from the WC produced by the demolition of the old building of Henan Polytechnic University, which was crushed by PE $125 \times 150$ jaw crusher after removing the steel bar and other impurities, and the crushed concrete blocks were directly put into the cement test mill of SM-500 model for grinding without sieving. A square-hole sieve with an aperture of $1.25 \mathrm{~mm}$ was used for screening after 10 minutes of grinding to make the particle size of the ground powder more uniform. The remaining particles on the sieve were treated as hard-togrind particles (which can be used as aggregates for recycled concrete). The powder after removing the hard-to-grind particles was put into the cement test mill to continue grinding. Particle size grading test, XRD analysis, and activity test were performed on the ground powder. The production process of WCP is shown in Figure 1.

2.1.1. Grinding Fineness and Time. The grinding fineness of WCP shall refer to the fineness standard of secondary fly ash. The residue of the secondary fly ash through the $45 \mu \mathrm{m}$ square-hole sieve should not exceed 30\% [23]. Malvern laser particle size analyzer was used to perform particle size grading tests on WC ground for 80,100 , and $120 \mathrm{~min}$. And the percentage of particles larger than $45 \mu \mathrm{m}$ is derived from the particle size distribution. The test result is shown in Figure 2. As shown in Figure 2(a), the volume density curve of WCP after grinding for $80 \mathrm{~min}$ shows two small peaks on the left and one large peak on the right, indicating that the WCP at this moment has a strong unevenness, and coarse particles account for a relatively high proportion. The volume density curve of grinding for 100 minutes has one less peak than that of grinding for 80 minutes, and the larger peak is on the left side, indicating that the particles are finer and more uniform at this time. The volume density curve at 120 minutes of grinding was similar to that at 100 minutes of grinding, so it was concluded that continued grinding did not significantly improve particle uniformity and fineness. As shown in Figure 2(b), the 100-minute grinding curve has a significant left shift compared to the 80-minute grinding curve, while the 120-minute grinding curve has only a very slight left shift compared to the 100-minute grinding curve. This phenomenon indicates that the grinding efficiency decreases gradually with the increase of grinding time. Fitting the percentage of particles larger than $45 \mu \mathrm{m}$ shows that the sieve allowance decreases exponentially with the increase of grinding time, indicating that the grinding efficiency decreases sharply. In this experiment, concrete powder with grinding duration of 100 minutes was selected for subsequent study due to the reduction of grinding efficiency.

2.1.2. XRD Analysis of WCP. The WCP was tested by Bruker $\mathrm{X}$-ray diffraction, and the test result is shown in Figure 3. The main mineral composition of WCP is calcite, dolomite, 


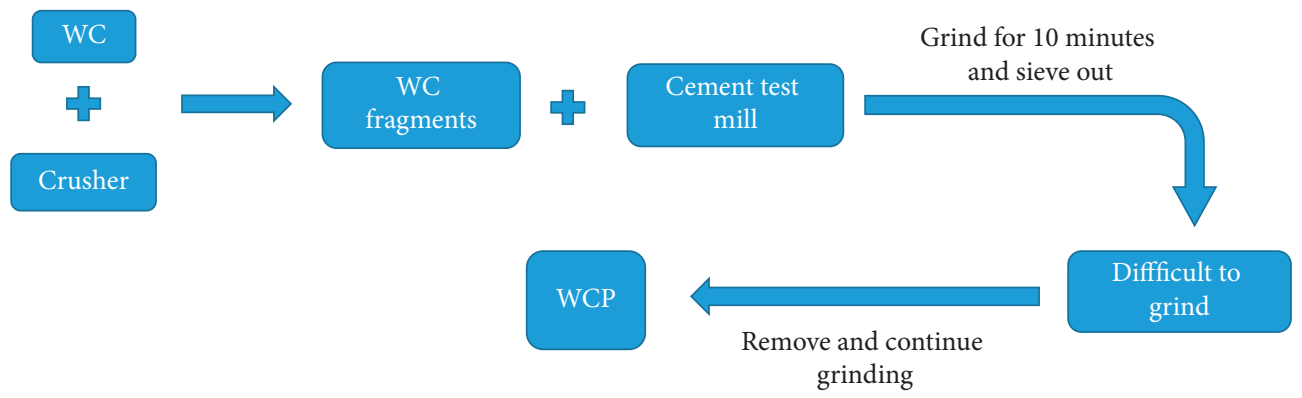

Figure 1: Production process of WCP.
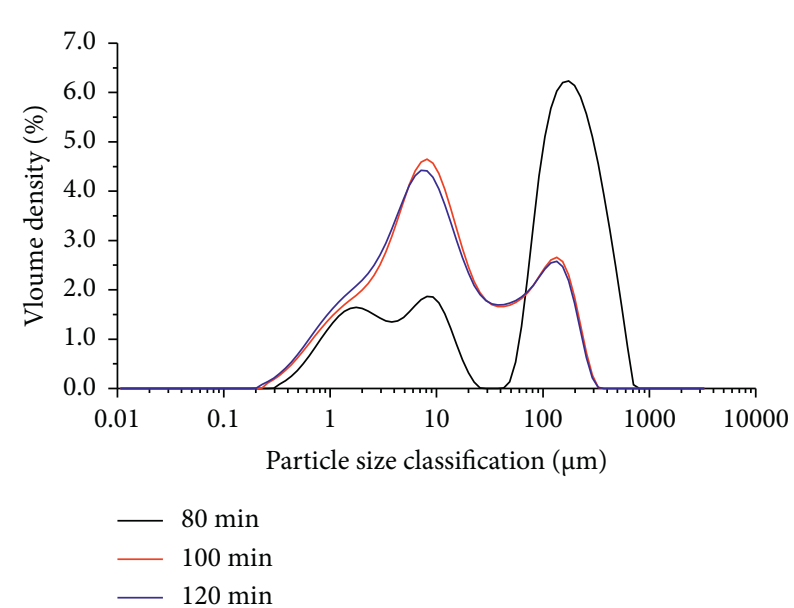

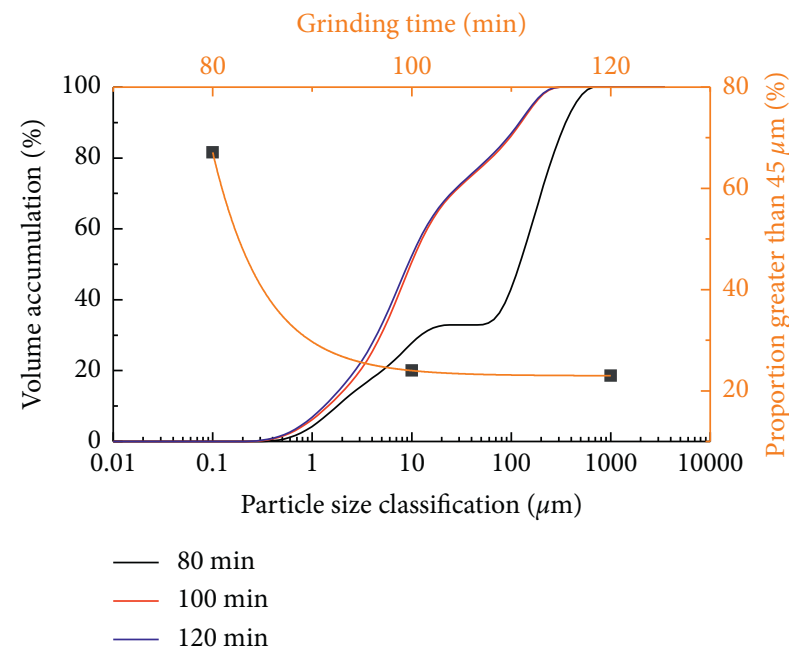

(b)

Figure 2: Particle size classification of WCP at different grinding times: (a) volume density, (b) particle size accumulation, and the proportion of particles greater than $45 \mu \mathrm{m}$.

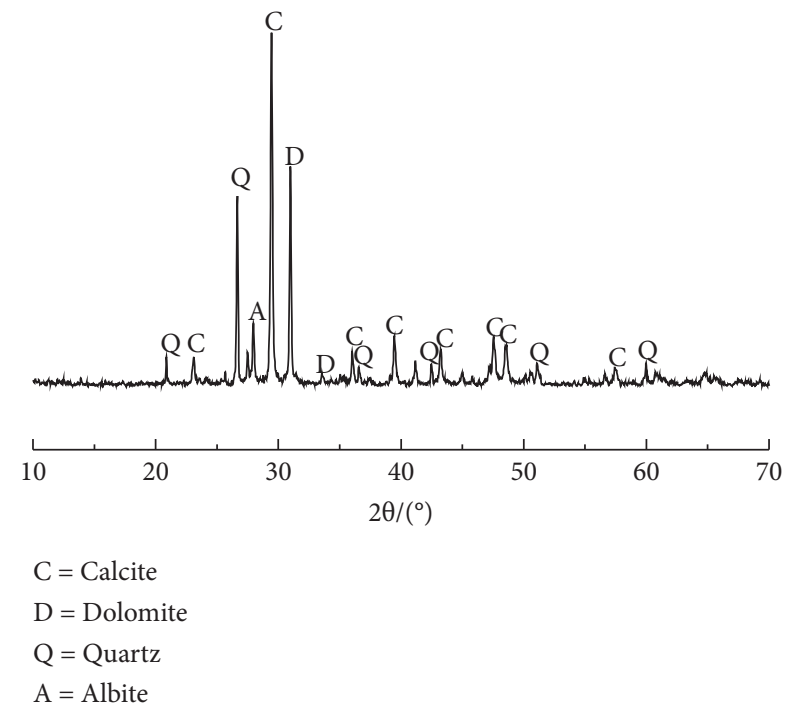

Figure 3: XRD pattern of WCP.

quartz, and sodium feldspar. The main component of calcite is $\mathrm{CaCO}_{3}$, which may be produced by the carbonization of $\mathrm{Ca}(\mathrm{OH})_{2}$ in concrete. The main component of quartz is $\mathrm{SiO}_{2}$.
$\mathrm{SiO}_{2}$ crystals with high crystallinity can play a filling role in the slurry, and the vitreous body $\mathrm{SiO}_{2}$ has volcanic ash activity, which can react with $\mathrm{Ca}(\mathrm{OH})_{2}$ to form hydrated calcium silicate [24].

2.1.3. Activity Test and SEM Scan of WCP. The activity index test of WCP was performed according to the standard GB/T 1596 [23]. The $40 \mathrm{~mm} \times 40 \mathrm{~mm} \times 160 \mathrm{~mm}$ specimens were poured according to the ratio of mortar sand as shown in Table 1. After 28 days of underwater curing, the specimens were tested for flexural strength and compressive strength, and the activity index was calculated according to (1). The activity index of WCP was calculated as 57\%. Apparently, the fineness of WCP milled for 100 min met the requirement but the activity was low. The reason is that the WC used in the test was generated by the demolition of the old brickconcrete structure, and its original strength is not high. Besides, the cement particles have basically been completely hydrated in the ages, so the activity stimulated by physical grinding is low.

$$
H_{28}=\left(\frac{R}{R_{0}}\right) \times 100,
$$


TABLE 1: Mixture ratio of mortar.

\begin{tabular}{lcccc}
\hline Type of mortar & Cement $(\mathrm{g})$ & WCP $(\mathrm{g})$ & Standard sand $(\mathrm{g})$ & Water $(\mathrm{ml})$ \\
\hline Reference mortar & 450 & - & 1350 & 225 \\
Test mortar & 315 & 135 & 1350 & 225 \\
\hline
\end{tabular}

where $H_{28}$ represents the activity index, and the unit is \%, $R$ represents the $28 \mathrm{~d}$ compressive strength of the test mortar, and the unit is $\mathrm{MPa}$, and $R_{0}$ represents the $28 \mathrm{~d}$ compressive strength of the reference mortar, and the unit is $\mathrm{MPa}$.

SEM scanning was performed on WCP to observe its morphology after grinding. The morphology of WCP under different magnifications is shown in Figure 4. As shown in Figure 4(a), the particle size of WCP is uneven, which is consistent with the results measured by the laser particle size analyzer. As shown in Figure 4(b), the cube-shaped $\mathrm{CaCO}_{3}$ crystals can be seen. Besides, as shown in Figure 4(c), it can be seen that the structure of the WCP is relatively loose and the surface is rough, containing particles bound by gel and a large number of the pores.

2.2. Method. According to the code (GB/51180-2016) [3], the water-solid ratio of the ground grouting in mine goaf is generally $1: 1-1: 1.3$. In this test, the water-solid ratio was fixed at $1: 1.1$, and pure cement slurry was set as the control group.

The test is an optimization test, which consists of two stages. In the first stage, the change rules of slurry viscosity, setting time, water-separation ratio, stone rate, and compressive strength were studied when the replacement rate of WCP was $50 \%, 60 \%, 70 \%, 80 \%$, and $90 \%$; the detailed test ratios are shown in Table 2. According to the test results of the first stage, the WCP70, WCP80, and WCP90 groups were optimized with naphthalene system water-reducing agent in the second stage to enhance the fluidity of the slurry, the detailed test ratios is shown in Table 3. It should be noted that the test results of indoor room temperature maintenance adopted in this test are suitable for the on-site conditions of less mine water.

Viscosity is the resistance of the fluid to flow, reflecting the fluidity of the slurry. The fluidity represents the injectability, which directly affects the diffusion radius of the slurry, and also determines the grouting pressure, flow rate, and other parameters $[25,26]$. In this test, the Brookfield DV2T viscometer was used to measure the viscosity of the slurry.

The setting time of the slurry is divided into two parts: the initial setting time and the final setting time. In order not to affect the flow and diffusion distance of the slurry, it is generally required that the initial setting time of the slurry should not be too short. In addition, the final setting time should not be too long; otherwise, it will affect the project activities and progress. This test uses a Vicat apparatus to determine the setting time of the slurry referring to the standard GB/T 1346 [27].

The water-separation ratio is an important indicator to measure the stability of the slurry. The higher the waterseparation ratio of the slurry, the more unstable the slurry, which will seriously affect the grouting effect. In this test, a measuring cylinder was used to test the water-separation ratio. The prepared slurry was poured into a $50 \mathrm{ml}$ cylinder and sealed with plastic wrap. The readings of the clear water at the upper part and the sediment at the bottom were observed and recorded until no more water came out. At this time, the ratio of the volume of clear water to the original volume is the water-separation rate of the slurry.

The stone rate of the slurry refers to the ratio of the solidified volume to the original volume. The higher the stone rate, the better the filling effect. In order to achieve good filling effect of ground in mine goaf, the stone rate of the slurry is usually required to be no less than $80 \%$. The measuring cylinder method was also used to test stone rate, injecting the slurry into the $50 \mathrm{ml}$ cylinder, sealing the mouth of the cylinder with plastic film. After 28 days at room temperature, the scale of the solidified slurry was recorded, and the ratio of the solidified volume to the original volume is taken as the stone rate of the slurry.

The test block is poured with a $70.7 \mathrm{~mm}$ triple test mold, and the compressive strength of the cube is measured with a universal testing machine. The value of the test block strength is carried out in accordance with the standard JGJ/T 70 [28].

\section{Results and Discussion}

The test results of the control group are shown in Table 4. The pure cement slurry had high compressive strength and good injectability and fluidity. However, the filling effect on the ground in mine goaf was not satisfactory due to the high ratio of water separation and low rate of stone formation. According to the grouting mechanism of ground in mine goaf, the new slurry can reduce the compressive strength, increase the stone rate, and prolong the setting time to a certain extent while maintaining good fluidity.

3.1. Only Adding WCP. Water-separation ratio and stone rate at different substitution rates are shown in Figure 5. It can be seen that the water-separation ratio of the slurry gradually decreased and the stone rate gradually increased as the replacement rate increased, indicating that the mixing of WCP can make the slurry more stable and the filling effect for ground in mine goaf better. This is due to a large amount of water absorbed by the pores on the surface of WCP particles, thus reducing the water-separation ratio and increasing the stone rate of the slurry. Not only that, but the sum of the water-separation ratio and the stone rate of the slurry in the same group was exactly equal to 1 , indicating that the sample will not show obvious shrinkage and expansion in the later curing process after the completion of water separation. 


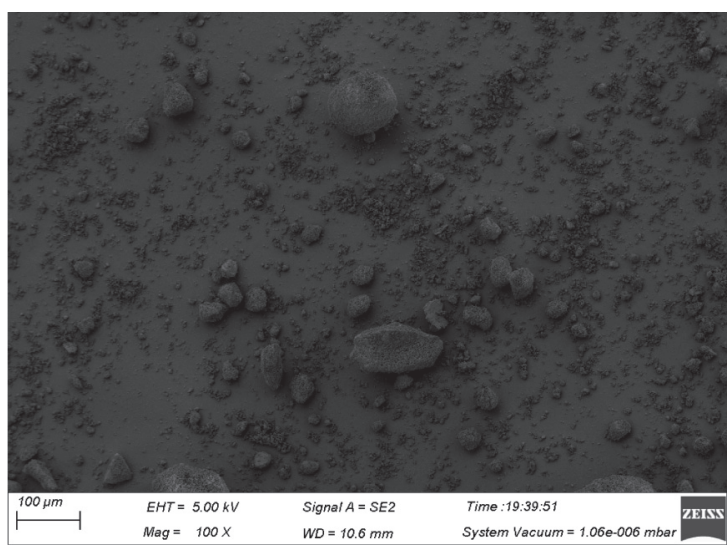

(a)

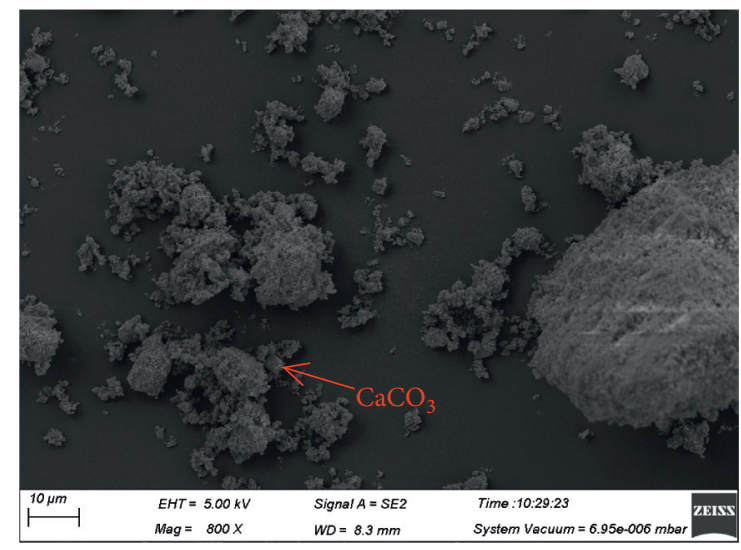

(b)

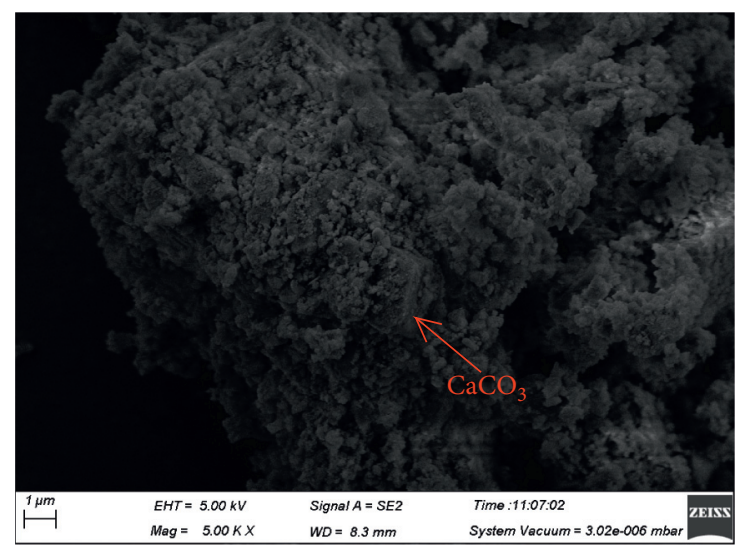

(c)

Figure 4: SEM images of WCP: (a) 100x, (b) 800x, and (c) 5000x.

TABle 2: Test ratios of phase 1.

\begin{tabular}{lcc}
\hline Group number & Cement content (\%) & WCP content (\%) \\
\hline WCP0 & 100 & 0 \\
WCP50 & 50 & 50 \\
WCP60 & 40 & 60 \\
WCP70 & 30 & 70 \\
WCP80 & 20 & 80 \\
WCP90 & 10 & 90 \\
\hline
\end{tabular}

Note. The group number in the table is "WCPa," where "a" means the mixing percentage.

The setting time at different substitution rates is plotted in Figure 6. As shown in the picture, the setting time of the slurry decreased slightly relative to the pure cement slurry when the replacement rate was 50\%. Afterwards, the initial setting time and final setting time of the slurry increased continuously with the increase of the replacement rate. In particular, the setting time increased greatly when the replacement rate exceeded $80 \%$.

As shown in Figure 7, the viscosity of the slurry increased when part of the cement was replaced by WCP, and the viscosity continued to rise with the increase of the replacement rate. This is due to a large amount of water absorbed by the pores on the surface of WCP particles, which increases the viscosity of the slurry.
Unconfined compressive strength (UCS) of specimen at different substitution rates is shown in Figure 8. The picture shows that the addition of WCP can significantly decrease the compressive strength, and the compressive strength of the specimen at all ages was continuously reduced with the increase of the replacement rate. The strength was reduced obviously due to the fact that the activity of the WCP was not high and the cementing material produced in the specimen decreased with the decrease of cement content.

3.2. Optimization of Water-Reducing Agent. High viscosity is the biggest problem for ground grouting in mine goaf with WCP according to the results of the first stage test, which will make the injectability and flow diffusion of slurry worse, thus affecting the grouting effect. To ameliorate this problem, water-reducing agent was added to the slurry to reduce the viscosity and increase the fluidity. To obtain a suitable slurry with a high substitution rate, the WCP70, WCP80, and WCP90 groups of slurries were selected in this experiment for subsequent study.

From the results of Figure 9, the viscosity of the slurry continued to decrease as the amount of water-reducing agent increased. Among them, the WCP70 group slurry could reach a viscosity similar to that of pure cement slurry by adding only $0.05 \%$ water-reducing agent. The viscosities 
TABle 3: Test ratios of phase 2 .

\begin{tabular}{lccc}
\hline Group number & Cement content (\%) & WCP content (\%) & Water-reducing agent content (\%) \\
\hline WCP70WR0.025 & 30 & 70 & 0.025 \\
WCP70WR0.05 & 30 & 70 & 0.05 \\
WCP80WR0.05 & 20 & 80 & 0.05 \\
WCP80WR0.1 & 20 & 80 & 0.1 \\
WCP90WR0.05 & 10 & 90 & 0.05 \\
WCP90WR0.1 & 10 & 90 & 0.1 \\
WCP90WR0.15 & 10 & 90 & 0.15 \\
\hline
\end{tabular}

Note. The group number in the table is WCPaWRb, where "WR" is water-reducing agent, and "a" and "b" represent the WCP and WR mixing percentage, respectively.

TABLE 4: Test results of the control group.

\begin{tabular}{|c|c|c|c|c|c|c|c|}
\hline \multicolumn{2}{|c|}{ Setting time $(\mathrm{min})$} & \multirow[t]{2}{*}{ Water-separation ratio (\%) } & \multirow[t]{2}{*}{ Stone rate $(\%)$} & \multirow[t]{2}{*}{ Viscosity $(\mathrm{cP})$} & \multicolumn{3}{|c|}{$\begin{array}{c}\text { Compressive strength } \\
(\mathrm{MPa})\end{array}$} \\
\hline Initial setting time & Final setting time & & & & $3 \mathrm{~d}$ & $7 \mathrm{~d}$ & $28 \mathrm{~d}$ \\
\hline 590 & 725 & 20 & 80 & 86.4 & 5.66 & 13.38 & 34.76 \\
\hline
\end{tabular}

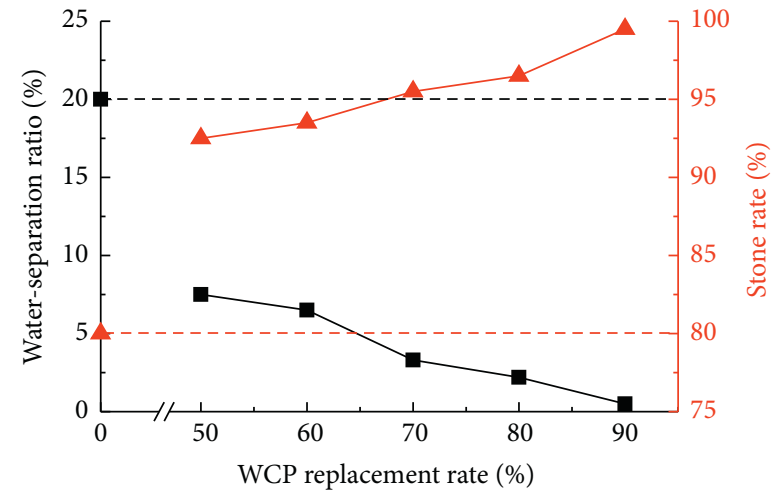

FIGURE 5: Water-separation ratio and stone rate at different substitution rates.

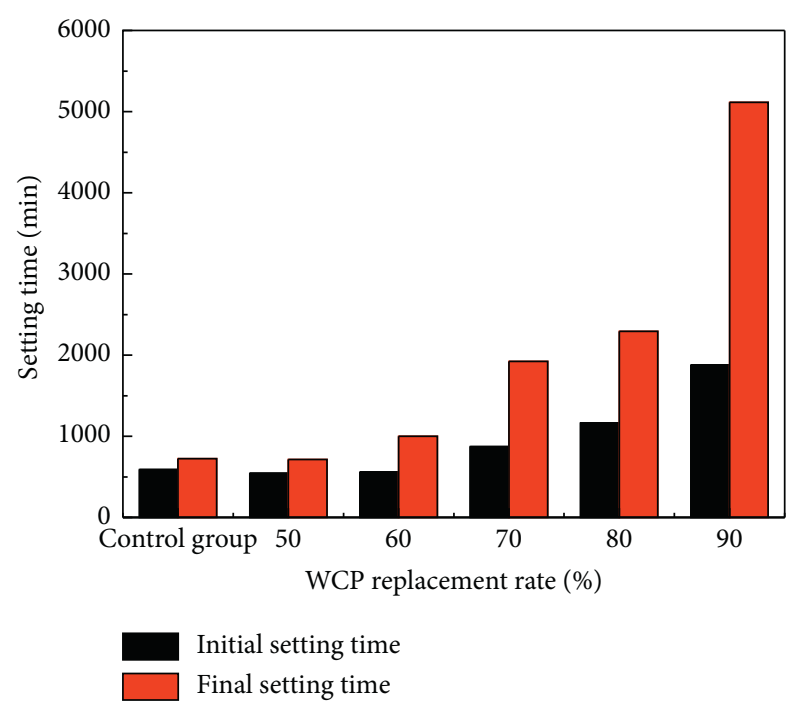

FIGURE 6: Setting time at different substitution rates.

of WCP80 and WCP90 slurries were also similar to that of the control group by adding $0.1 \%$ and $0.15 \%$ water-reducing agent, respectively. The improvement of fluidity results from

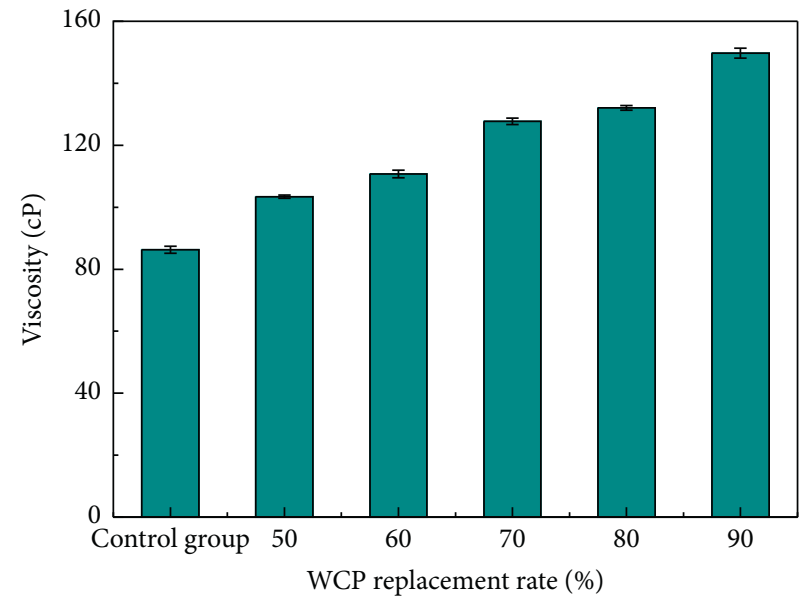

FIGURE 7: Viscosity at different substitution rates.

the absorption of negatively charge water-reducing agent which increases the electrostatic repulsion and lubricity between cement particles [29].

Although the addition of water-reducing agent can reduce the viscosity of the slurry, it will inevitably affect other properties. From Figure 10(a), the water-separation ratio of slurry was rising and the stone rate of serous fluid decreased slightly with the increase of water-reducing agent. The waterreducing agent particles attached to the surface of WCP reduced the water absorption and increased the water-separation ratio of the slurry. Besides, the sum of the waterseparation ratio and the stone rate of the slurry in the same group was exactly equal to 1 , indicating that the incorporation of water-reducing agent will not cause obvious shrinkage and expansion of the slurry in the later curing process after the completion of water separation. From Figure 10(b), it can be seen that the stone rate of the three kinds of newly prepared slurry is higher than pure cement slurry and the water-separation ratio was much lower than pure cement slurry, indicating that the newly prepared slurry is more stable and has a good filling effect on the ground in mine goaf. 


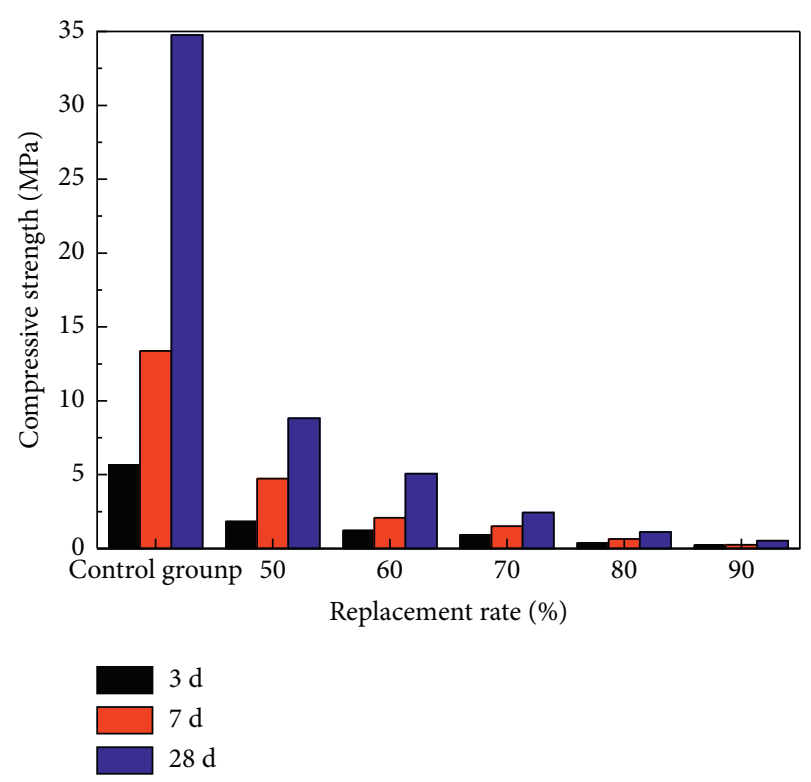

FIgURE 8: Compressive strength at different substitution rates.

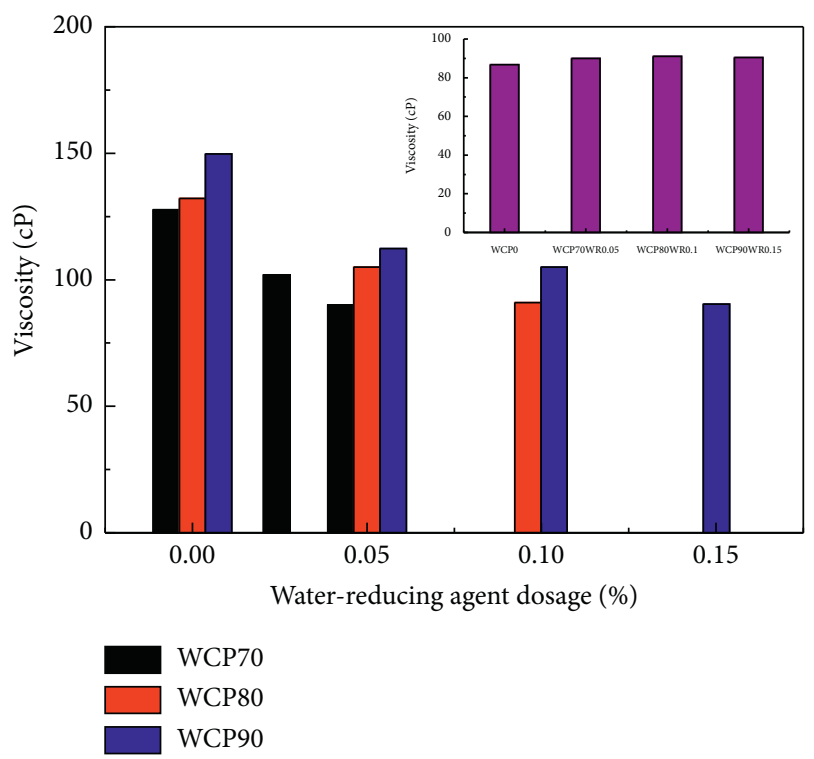

FIGURE 9: Viscosity after adding water-reducing agent.

As shown in Figure 11(a), the incorporation of waterreducing agent prolonged the setting time of the slurry, but the setting time showed a slower and slower increase and the growth rate gradually decreased as the number of incorporations increased, which was in a relatively stable state. From Figure 11(b), it can be seen that the setting time of the three newly configured WCP-Cement grouts is greater than that of pure cement slurry, which is more conducive to the flow and diffusion of grout. However, the final setting time of WCP90WR0.15 group slurry is close to 4 days, which may affect the project progress to some extent and should be carefully selected according to the site situation and construction period requirements.

The results in Figure 12(a) indicated that the uniaxial compressive strength of WCP80 and WCP90 groups decreased as the amount of water-reducing agent was increased. For the WCP70 group, the strength in the early stage had little change after adding different doses of waterreducing agent, but in the middle and late stage it showed a trend of first decreasing and then increasing. This may be due to the fact that the WCP70 group had relatively lower WCP content and poorer water absorption, which increased the water-separation ratio. The increase of water-separation ratio is equivalent to the decrease of the water-solid ratio of slurry, which makes the strength of specimen increase. Therefore, when the amount of water-reducing agent was small, the compressive strength of the specimens affected by the water-reducing agent decreased. When the amount of water-reducing agent was increased, the compressive strength of the specimens was slightly increased by the higher ratio of water-separation but still is less than the components without adding water-reducing agent.

As shown in Figure 12(b), the compressive strength of the WCP-Cement slurry was much lower than that of pure cement slurry. Based on the code (GB 51180-2016) [3], the 28-day compressive strength should not be less than $2 \mathrm{MPa}$, so the WCP70WR0.05 group is the most suitable component. Although the 28-day strength of the WCP80WR0.1 test piece was less than $2 \mathrm{MPa}$, it had good other properties and can be used for ground in mine goaf which is not within the main stress layer of building foundations according to the site conditions.

Cement is expensive and the production process emits a lot of $\mathrm{CO}_{2}$, which causes great pollution to the environment [30-32]. According to the grouting requirements of ground in mine goaf, replacing cement with WCP can greatly enhance the green environmental protection of the slurry. In terms of economy, the unit price of naphthalene waterreducing agent is about ten times that of cement, but the amount is only one-thousandth of the total mass of solid. Therefore, WCP-Cement slurry can save a lot of cost compared to pure cement slurry. However, it is worth noting that WC is hard to grind and consumes more electricity in the grinding process, so we should consider upgrading grinding equipment or adding grinding aid to further reduce cost and improve economic efficiency.

3.3. XRD. XRD patterns of the WCP70WR0.05 group samples at $7 \mathrm{~d}$ and $28 \mathrm{~d}$ are shown in Figure 13. The figure shows that the main phases in the sample are gypsum, dolomite, calcium hydroxide, calcium carbonate, and silicon dioxide. Gypsum comes from cement, calcium hydroxide is produced during cement hydration, and the remaining phases come from WCP.

Comparing the 7-day and 28-day spectra, we found that the peaks' positions and numbers at different ages of the specimens were basically the same, indicating that the matrix phases of the specimens at different ages were the same, and the increase in age would not cause the specimens to produce new phases, nor would it cause the original phases to disappear. From the figure, it is found that although the positions of the peaks are almost the same, there are different degrees of changes in their peak heights, indicating that 


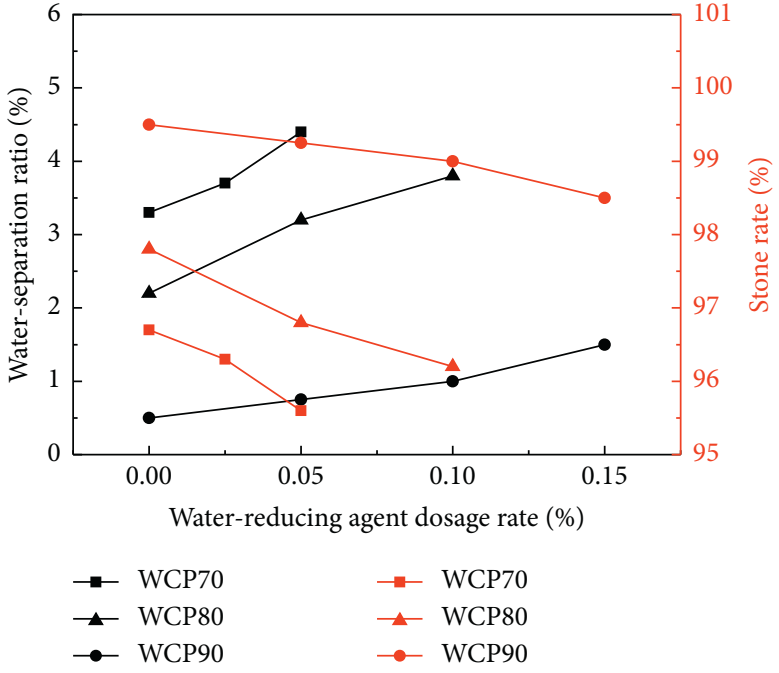

(a)

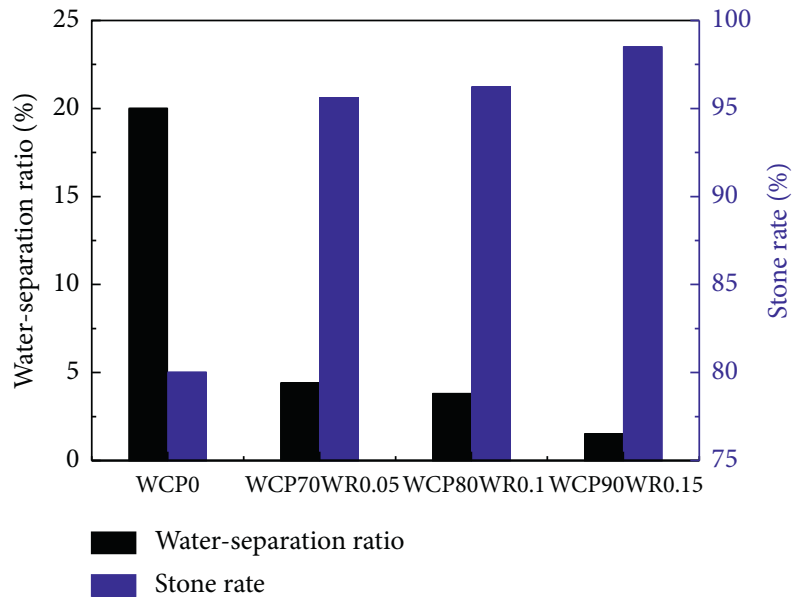

(b)

FIGURE 10: Water-separation ratio and stone rate after adding water-reducing agent: (a) change rule and (b) comparison of slurries with similar viscosity.

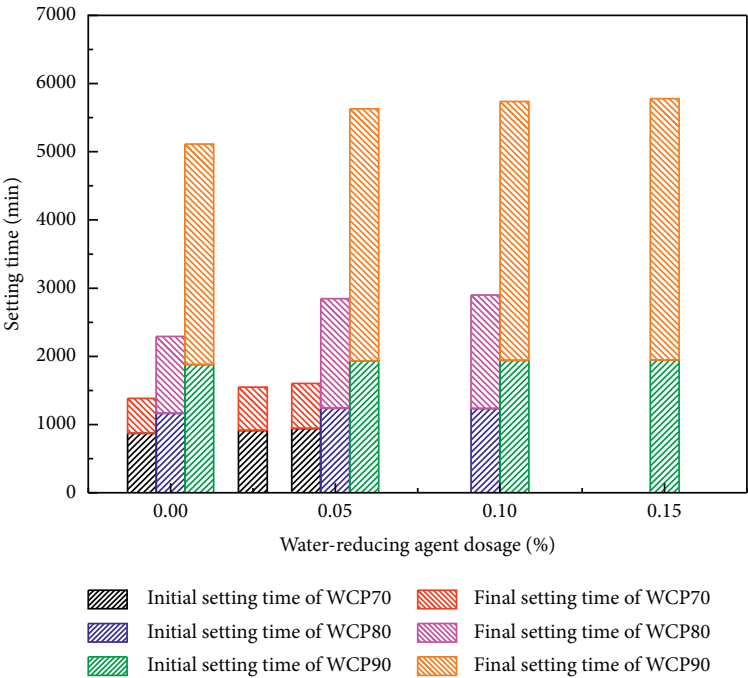

(a)

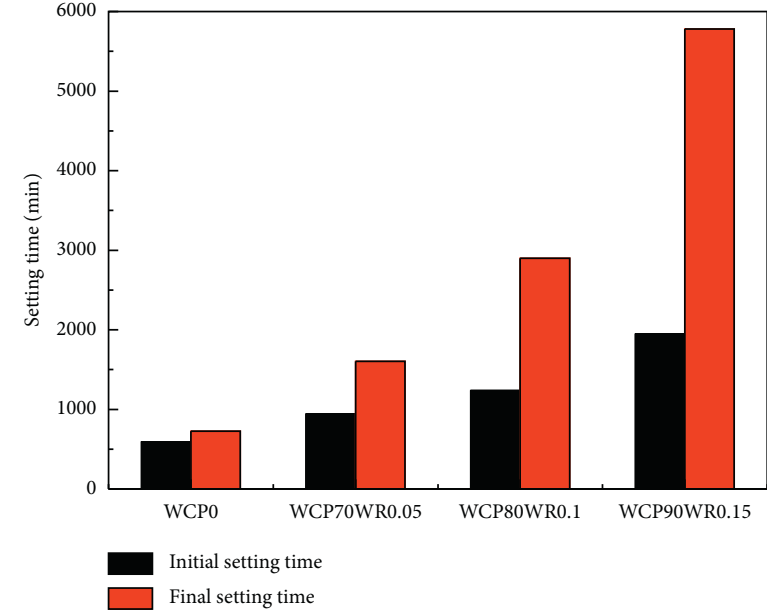

(b)

FIGURE 11: Setting time after adding water-reducing agent: (a) change rule and (b) comparison of slurries with similar viscosity.

changes in maintenance age have an effect on the degree of crystallization of the phase.

3.4. SEM. The fraction with $70 \%$ substitution and $0.05 \%$ water-reducing agent addition (WCP70WR0.05) was scanned by SEM and analyzed for $7 \mathrm{~d}$ and $28 \mathrm{~d}$ microscopic morphological changes.

The morphology of the sample under different magnifications after 7 days of curing is shown in Figure 14. As shown in Figure 14(a), there were a large number of pores on the surface of the specimen, and the structure of it was relatively loose. In addition to pores, ettringite (AFt), calcium hydroxide $(\mathrm{CH})$, and gel $(\mathrm{CSH})$ were seen in the sample from Figure 14(b). AFt provided early strength and
$\mathrm{CH}$ created an alkaline environment for the later reaction. Besides, the surface of the specimen was covered with a large number of $\mathrm{CaCO}_{3}$ crystals, which were derived from WCP and were mainly used for filling. It can also be found from Figures 14(b) and 14(c) that the AFt was similar to fibrous distribution, $\mathrm{CaCO}_{3}$ crystal was cubic distribution, and $\mathrm{CH}$ was flake like hexagon distribution, and they covered the surface of CSH together.

The morphology of the sample under different magnifications after 28 days of curing is shown in Figure 15. Comparing Figure 15(a) with Figure 14(a), it can be seen that the number of pores and the pore diameter of the sample were reduced in the later stage. Some of the original pores were filled with more cementing materials in the later period with the progress of hydration reaction, which made the 


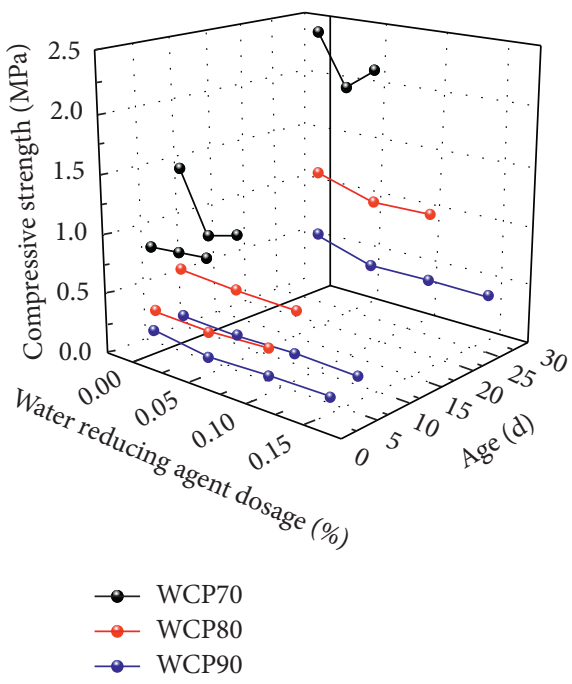

(a)

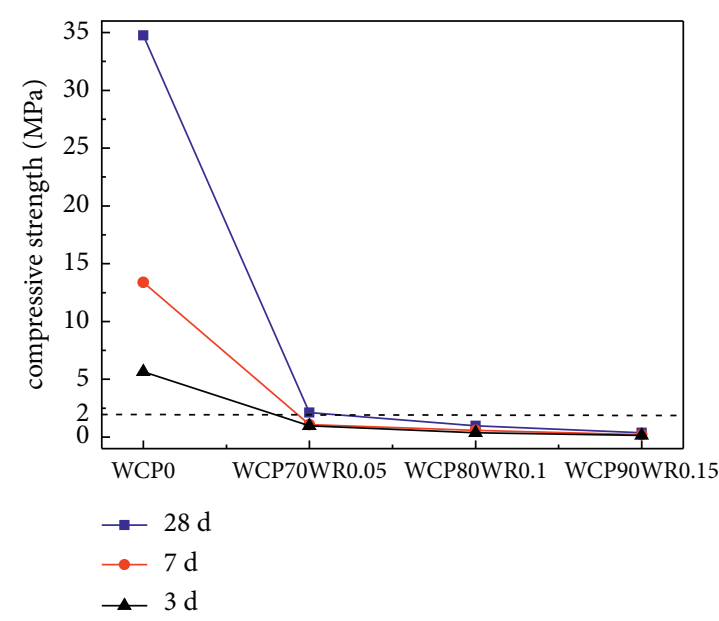

(b)

FiguRE 12: Compressive strength of test samples at different water-reducing agent dosages: (a) change rule and (b) comparison of slurries with similar viscosity.

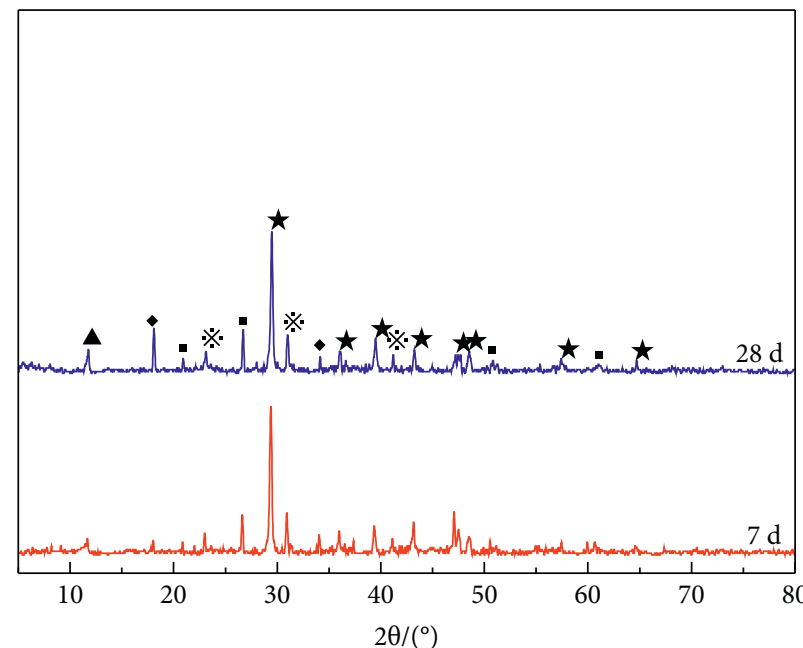

$$
\begin{array}{ll}
\text { ム } & - \text { Gypsum } \\
\text { ※ } & -- \text { Dolomite } \\
\text { - } & -\mathrm{Ca}(\mathrm{OH})_{2} \\
\star & --\mathrm{CaCO}_{3} \\
\text { - } & -\mathrm{SiO}_{2}
\end{array}
$$

FIGURE 13: XRD patterns of WCP70WR0.05 group at 7 and 28 days.

structure of the sample more compact. Comparing the 8000 times magnified images in Figures 14(b) and 15(b), the $\mathrm{CH}$ and $\mathrm{CaCO}_{3}$ crystals are invisible in the later stage. This is due to the fact that fewer gels were produced in the early stage, which can only have a slight bonding effect on $\mathrm{CaCO}_{3}$ and $\mathrm{CH}$. However, the increasing amount of gels in the later stage can cover both of them. Besides, there were slight changes in the morphology of AFt at different ages. The AFt in the early stage was mainly distributed in a similar fiber shape, and in the later stage, it was mainly inserted in the gel in the shape of needles or short columns, which looked more rigid. The $\mathrm{CH}$ was wrapped up by the $\mathrm{CSH}$ seen in Figure 15(c) at 12000x magnification, so it is difficult to see it in the low magnification image. 


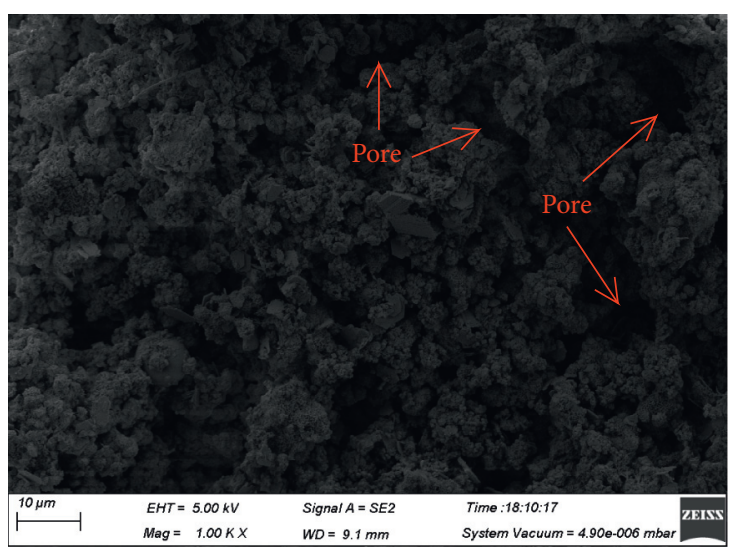

(a)

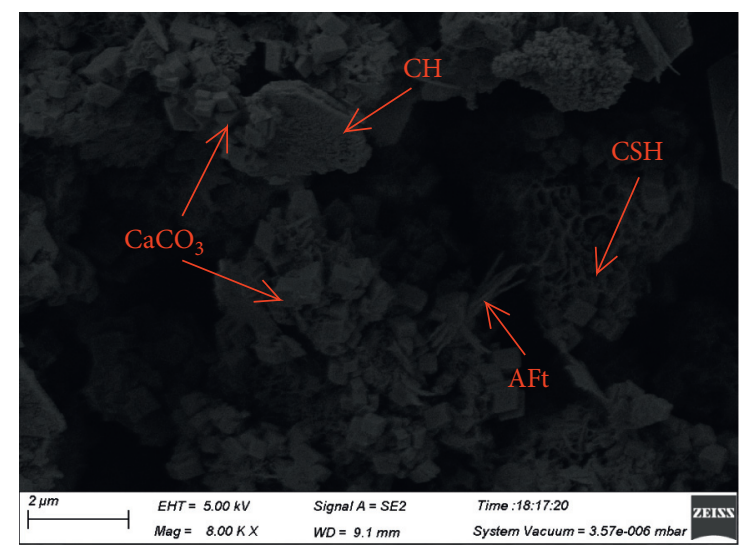

(b)

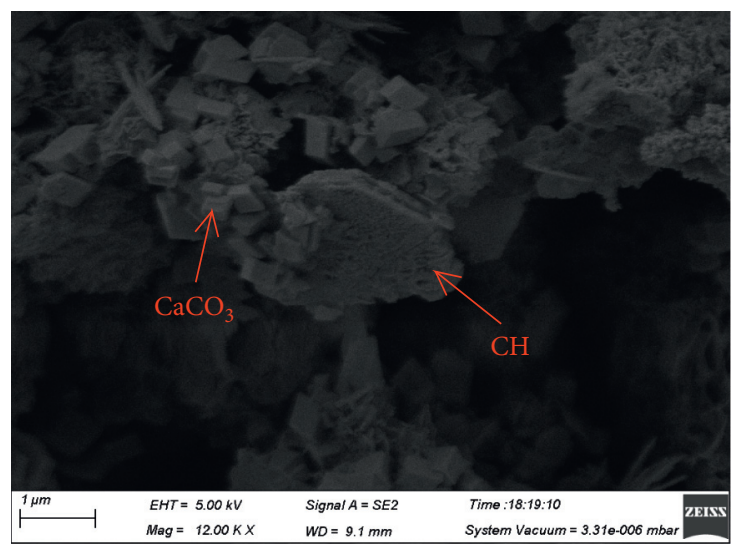

(c)

Figure 14: SEM images of the specimen for 7 days: (a) 1000x, (b) 8000x, and (c) 12000x.

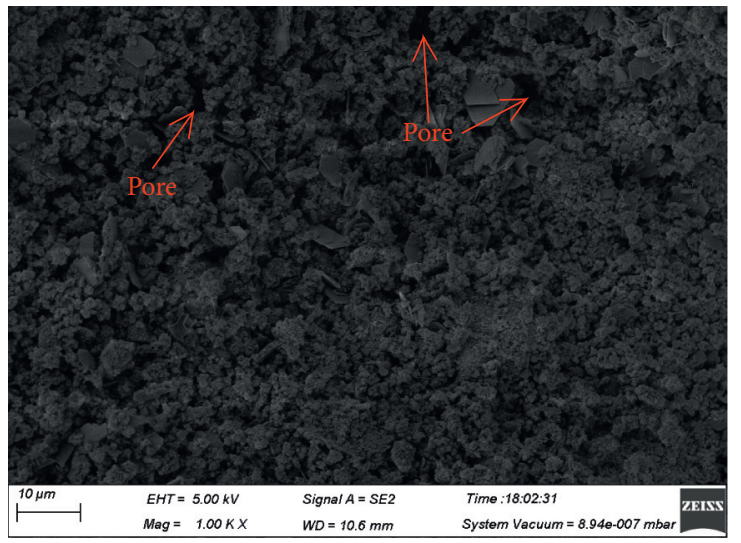

(a)

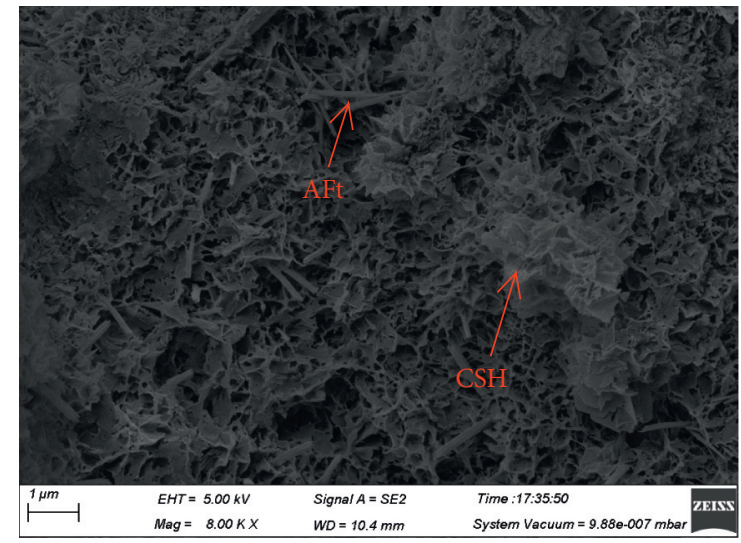

(b)

FIgURE 15: Continued. 


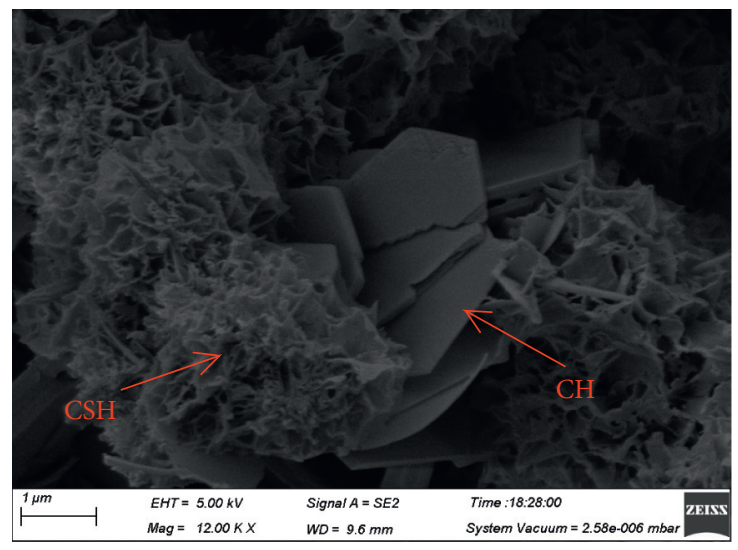

(c)

FIGURE 15: SEM images of the specimen for 28 days: (a) 1000x, (b) 8000x, and (c) 12000x.

\section{Conclusions}

In order to use waste concrete powder (WCP) in grouting for ground improvement in mine goaf site, WCP-Cement slurry with replacing $50 \%-90 \%$ of cement is proposed and studied. The influence factors of setting time, fluidity, water-separation ratio, stone rate, and compressive strength were studied, and an environmentally friendly slurry suitable for ground treatment in mine goaf is optimized by adding water-reducing agent later. Suitable matched specimens were sampled for XRD and SEM microanalysis to study the cementation grouting mechanism from the view of microstructure. The following conclusions can be drawn:

(1) The water-separation ratio of slurry decreases and the stone rate increases as the replacement rate of WCP increases, but the viscosity continues to increase, which makes the fluidity and injectability of the slurry worse, so it is necessary to add waterreducing agent to optimize the slurry.

(2) The slurry made up of $30 \%$ cement, $70 \%$ WCP, and $0.05 \%$ naphthalene-based water-reducing agent has the obvious advantages of high stone rate and good injectability. Besides, other properties of it also meet the grouting requirements of the ground in mine goaf, which is an economical and environmentally friendly filling material.

(3) The slurry prepared with $20 \%$ cement, $80 \%$ WCP, and $0.10 \%$ naphthalene-based water-reducing agent also has significant advantages of high stone rate and good injectability, but its $28 \mathrm{~d}$ uniaxial compressive strength is less than $2 \mathrm{MPa}$. It can be used in ground in mine goaf which is not within the main stress layer of building foundations according to the site conditions.

(4) The activity of WCP produced by mechanical grinding is low, and it is difficult to supplement the strength of the specimen. However, fine WCP particles can exert microaggregate effect in the slurry and enhance the compactness of the stone body.

\section{Data Availability}

The data used to support the findings of this study are included within the article.

\section{Conflicts of Interest}

The authors declare that they have no conflicts of interest regarding the publication of this paper.

\section{Acknowledgments}

This work was supported by the National Natural Science Foundation of China (no. U1810203).

\section{References}

[1] X. F. Ao, X. L. Wang, X. B. Zhu, Z. G. Zhou, and X. X. Zhang, "Grouting simulation and stability analysis of coal mine goaf considering hydromechanical coupling," Journal of Computing in Civil Engineering, vol. 31, no. 3, 2017.

[2] K. Rong, W. Lan, and H. Li, "Industrial experiment of goaf filling using the filling materials based on hemihydrate phosphogypsum," Minerals, vol. 10, no. 4, pp. 324-340, 2020.

[3] GB 51180-2016, China Standard, Technical Code for Ground Treatment of Buildings in Coal Mine Goaf, Chinese Standards Association, Beijing, China, 2016.

[4] L. W. Ren, G. L. Zhou, Z. L. Dun, T. Y. He, Q. W. Yang, and M. H. Zhang, "Case study on suitability and settlement of foundation in goaf site," Rock and Soil Mechanics, vol. 39, no. 8, pp. 2922-2932, 2018.

[5] Z. F. Li, J. Zhang, S. C. Li, Y. F. Gao, C. Liu, and Y. H. Qi, "Effect of different gypsums on the workability and mechanical properties of red mud-slag based grouting materials," Journal of Cleaner Production, vol. 245, 2020.

[6] F. Sha, C. Lin, Z. Li, and R. Liu, "Reinforcement simulation of water-rich and broken rock with portland cement-based grout," Construction and Building Materials, vol. 221, pp. 292-300, 2019.

[7] F. Sha, S. Li, R. Liu, Q. Zhang, and Z. Li, "Performance of typical cement suspension-sodium silicate double slurry grout," Construction and Building Materials, vol. 200, no. 10, pp. 408-419, 2019. 
[8] S. Li, F. Sha, R. Liu, Q. Zhang, and Z. Li, "Investigation on fundamental properties of microfine cement and cement-slag grouts," Construction and Building Materials, vol. 153, no. 30, pp. 965-974, 2017.

[9] Y. Zhou, G. H. Wang, and Y. F. Yuan, "Basic properties and engineering application of bentonite-cement-water glass grouting," KSCE Journal of Civil Engineering, vol. 24, no. 9, 2020.

[10] F. Perez-Garcia, M. D. Rubio-Cintas, M. E. Parron-Rubio, and J. M. Garcia-Manrique, "Advances in the analysis of properties behaviour of cement-based grouts with high substitution of cement with blast furnace slags," Materials, vol. 13, no. 3, pp. 561-574, 2020.

[11] X. Zhu, Q. Zhang, W. Zhang, J. Shao, Z. Wang, and X. Wu, "Experimental study on the basic properties of a green new coal mine grouting reinforcement material," ACS Omega, vol. 5, no. 27, Article ID 16722, 2020.

[12] L. Y. Tong, S. Pan, and Y. Qiu, "Experimental study on grouting filling materials with large amount of fly ash," Journal of Southeast University (Natural Science Edition), vol. 32, no. 4, pp. 643-647, 2002.

[13] J. Shao, J. Gao, Y. Zhao, and X. Chen, "Study on the pozzolanic reaction of clay brick powder in blended cement pastes," Construction and Building Materials, vol. 213, pp. 209-215, 2019.

[14] L. H. Li, L. L. Qin, H. L. Xiao, Z. Hu, Y. Y. Pei, and J. Tong, "Large dynamic triaxial test study on reinforcement mechanisms of reinforced construction waste," Chinese Journal of Rock Mechanics and Engineering, vol. 39, no. 8, pp. 1682-1695, 2020.

[15] Z. Guo, A. Tu, C. Chen, and D. E. Lehman, "Mechanical properties, durability, and life-cycle assessment of concrete building blocks incorporating recycled concrete aggregates," Journal of Cleaner Production, vol. 199, pp. 136-149, 2018.

[16] J. F. Zhang, Y. M. Huang, F. Aslani, G. W. Ma, and B. T. Nener, "A hybrid intelligent system for designing optimal proportions of recycled aggregate concrete," Journal of Cleaner Production, vol. 273, 2020.

[17] E. H. Sanchez-Cotte, L. Fuentes, G. Martinez-Arguelles, H. A. Rondón Quintana, L. F. Walubita, and J. M. CanteroDurango, "Influence of recycled concrete aggregates from different sources in hot mix asphalt design," Construction and Building Materials, vol. 259, 2020.

[18] H. X. Luan, J. Wu, and J. Y. Pan, "Saline water absorption behavior and critical saturation degree of recycled aggregate concrete during freeze-thaw cycles," Construction and Building Materials, vol. 258, 2020.

[19] C. B. Xiong, W. Chen, M. Shen, and Z. Li, "Experimental investigation on recycled clay brick powder as a sand replacement in LFC," Magazine of Concrete Research, vol. 71, no. 23, pp. 1-23, 2018.

[20] J. Xiao, Z. Ma, T. Sui, A. Akbarnezhad, and Z. Duan, "Mechanical properties of concrete mixed with recycled powder produced from construction and demolition waste," Journal of Cleaner Production, vol. 188, no. 1, pp. 720-731, 2018.

[21] E. Kwon, J. Ahn, B. Cho, and D. Park, "A study on development of recycled cement made from waste cementitious powder," Construction and Building Materials, vol. 83, pp. 174-180, 2015.

[22] X. Y. He, Z. Q. Zheng, J. Yang, Y. Su, T. G. Wang, and B. M. Strnadel, "Feasibility of incorporating autoclaved aerated concrete waste for cement replacement in sustainable building materials," Journal of Cleaner Production, vol. 250, 2019.
[23] GB/T 1596-2017, China Standard, Fly Ash Used for Cement and Concrete, Chinese Standards Association, Beijing, China, 2017.

[24] C. L. Wong, K. H. Mo, S. P. Yap, U. J. Alengaram, and T.-C. Ling, "Potential use of brick waste as alternate concretemaking materials: a review," Journal of Cleaner Production, vol. 195, no. 10, pp. 226-239, 2018.

[25] J. Liu, N. Q. Hu, B. J. Xu, X. Yue, B. QI, and Q. Zhong, "Experiment of cement-based seepage grouting materials for earth-rock dam," Journal of Shandong University, vol. 48, no. 2, pp. 39-45, 2008.

[26] F. Sha, Q. Jin, and P. Liu, "Development of effective microfine cement-based grouts (EMCG) for porous and fissured strata," Construction and Building Materials, vol. 262, 2020.

[27] GB/T 1346-2011, China Standard, Test Methods for Water Requirement of Normal Consistency, Setting Time and Soundness of the Portland Cement, Chinese Standards Association, Beijing, China, 2011.

[28] Jgj/T70-2009, China Standard, Standard for Test Method of Performance on Building Mortar, Chinese Standards Association, Beijing, China, 2009.

[29] L. Yang, E. Yilmaz, J. Li, H. Liu, and H. Jiang, "Effect of superplasticizer type and dosage on fluidity and strength behavior of cemented tailings backfill with different solid contents," Construction and Building Materials, vol. 187, pp. 290-298, 2018.

[30] R. M. Andrew, "Global $\mathrm{CO}_{2}$ emissions from cement production, 1928-2018," Earth System Science Data, vol. 11, no. 4, pp. 1675-1710, 2019.

[31] H. S. Hassan, H. A. Abdel-Gawwad, S. R. Vasquez-Garcia et al., "Cleaner production of one-part white geopolymer cement using pre-treated wood biomass ash and diatomite," Journal of Cleaner Production, vol. 209, pp. 142-1428, 2019.

[32] X. H. Zhao, C. Y. Liu, L. M. Zuo et al., "Synthesis and characterization of fly ash geopolymer paste for goaf backfill: reuse of soda residu," Journal of Cleaner Production, vol. 260, 2020. 